\title{
If fibromyalgia did not exist, we should have invented it. A short history of a controversial syndrome
}

\section{S. Perrot}

Service de Médecine Interne et Thérapeutique, Paris Descartes University, Hôtel Dieu Hospital, Paris, France

\section{SUMMARY}

Fibromyalgia is a recent disease, and some physicians remain doubtful about its reality. The history of fibromyalgia is a story of controversies: the fight between subjectivity and cartesianism, and between old mind and body concepts. Fibromyalgia represents the emblematic condition of unexplained medical symptoms, far from well-defined diseases with objective biomarkers. In this review we will follow the fibromyalgia story along the ages and sciences to better understand this complex pain disorder, between soma and psyche, and between medicine and psycho-sociology and to demonstrate that fibromyalgia exist, we have not invented it.

Key words: Fibromyalgia, fibrosiitis, myalgia, tender points.

Reumatismo, 2012; 64 (4): 186-193

\section{INTRODUCTION}

1 ibromyalgia is a recent disease (1), and some physicians remain doubtful about its reality. In 1926, Hunter had already stated that "it requires a little courage to present a paper on this subject, for fibrositis, or myalgia, has no generally recognised pathology and the term has in the past been used very loosely to cover many pathological conditions" (2). In fact, the name "fibromyalgia" is recent, proposed by Hench (3) in 1976, but the story began long before this labelling.

Over time, its story has been influenced by current concepts, from muscle to psychology, from genetics to hormones, and finally with important findings related to the neurosciences.

We will follow this story along the ages and sciences to better understand this complex pain disorder, between soma and psyche, and between medicine and psychosociology.

This story aims to demonstrate that patients have existed all throughout the centuries, and that if fibromyalgia did not exist, we should have invented it.
At the beginning: greek and roman literature "Joint pain is driven by the brain"

The history of pain medicine and rheumatology is very old, and it is possible to find interesting concepts and descriptions of pain in ancient Greek literature. In 410 BC, Hippocrates (430-380 BC) described the "Rheuma Theory": a mechanism of pain where the brain sends liquid to the lower limb, and when there is more liquid, there is more pain. Rheuma means fluid in Greek, and in fact, the Rheuma theory explains the influence of the brain on the body (4).

It is interesting to note that this concept is close to the recent concepts of central sensitization. Hippocrates was one of the first to consider that pain is not a punishment but a natural phenomenon. He also described the use of nonpharmacological tools to relieve pain: cold and hot application, and plasters (4).

After Hippocrates, Theophrastes (372 BC287 BC), a Greek physician who was one of Aristoteles disciples, described widespread pain conditions. Theophrastes published the "characters" where he described a feature of general pain in muscles and ten- 
dons, as a special condition that he called "lassitude." Four-hundred years later, Galien (131-201 AD) also tried to classify pain symptoms. He stated that the brain is the center of pain and all sensations. In his system, pain was the result of soul disorders and passions.

The very first medical description of fibromyalgia in Renaissance times

Guillaume de Baillou (1538-1616) was a physician (Dean of the University of Paris medical faculty, 1580), and founder of modern epidemiology who revived Hippocratic medical practice in Renaissance Europe $\mathrm{He}$ was the first to define the term "rheumatism" in its modern sense. In 1592 he published a book "Liber de rheumatismo", in which there are some descriptions of muscular pain close to fibromyalgia. This is probably the very first medical description of fibromyalgia.

Starting to establish pathophysiology: fibromyalgia as a muscle disorder

In the $19^{\text {th }}$ century, the first pathophysiological approaches emerged, and fibromyalgia was described as "muscular rheumatism." In the $19^{\text {th }}$ century, concomitantly, several European authors described similar clinical syndromes with widespread pain localised in the muscles.

Xavier Bichat (1771-1802) was one precursor of muscular theories and established the tissular theory: from the greek iotós = "tissue". He published in 1799 "Traité des membranes en général et des diverses membranes en particulier," where he described 21 varieties of tissue, considering distinct characteristics and diseases. In 1800, he was established in Hôtel-Dieu where he applied the clinical-anatomical method (5).

An important step was made by William Balfour (6), a surgeon in Edinburgh who was the first, in 1815, to describe "muscular rheumatism": "A special pain, usually driven by an inflammatory action, involving fibrous and white tissues, belonging to muscles and joints, like tendons, aponevroses". He called this widespread pain "fibrosistitis."

\section{The tender points}

The tender points were described by Valleix in France, in 1841 (7). He described referred pain triggered while certain painful points were palpated. Just after, in 1858, in Great Britain, Inman described a muscular localised pain independent of innervation and also "referred pain" (8). Concomitantly, in Germany, Froriep (1843) (9) described nodules in the muscles with pain induced by pressure and in 1903, Cornelius (10) described "nervous points" in the muscle, with pain influenced by weather and emotions.

\section{Toward the description of fibrositis}

There have been concomitant descriptions of features of widespread pain, mostly related to muscles.

In 1876, in Sweden, Helleday described myositis (11).

In 1904, Gowers (12) introduced the term "fibrositis" to describe the inflammation of fibrous tissue in his description of low back pain. In the same year, the pathologist Stockman (13) first reported evidence of inflammatory changes in the fibrous, intramuscular septa (a thin membrane that divides two soft masses of tissue) in biopsies from patients.

However, subsequent studies of muscle biopsies have failed to reproduce Stockman's findings of inflammation, and the term "fibrositis" is therefore considered a misnomer (14).

After the description of fibrositis, Telling described nodular fibromyositis (15) and was the first to try to unify different disorders with different names, describing the same pathophysiological entity. Cyriax, was a British physician, widely known as the father of orthopedic medicine. He believed that muscle pain derived from nerve impingement due to disc degeneration and also reported more precise fibrositis features (16). In 1952, Janet Travell coined the word "myofascial" and the myofascial pain syndrome (17).

All these theories on the muscle pathophysiology have not been confirmed, and only muscle microcirculation and metabolic abnormalities have been found (18). 
The end of the $19^{\text {th }}$ and the start of the $20^{\text {th }}$ century: the golden era of psychology

The end of the $19^{\text {th }}$ century and the $20^{\text {th }}$ century can be considered as the era of psychology, with several schools of psychology. Among the most famous: in North America (William James), in Austria (Sigmund Freud, Joseph Breuer), France (JeanBaptiste Charcot), and Germany (Wilhelm Wundt). This was also the specific rise of psychoanalysis with Freud and his disciples.

\section{Neurasthenia}

A very interesting condition, surprisingly very close to the ACR 2010 criteria of fibromyalgia has been described in 1869 under the name of neurasthenia, described by G.M. Beard (19) (Figure 1, Table I).

Psychogenic and psychosomatic rheumatism

In this line, fibromyalgia was considered a psychological disorder, with several new

Table I - Criteria for neurasthenia described by Beard (1869).

\begin{tabular}{|l|}
\hline - Cephalalgia \\
\hline - Insomnia, nightmares \\
\hline - Rachialgia, coccygodynia \\
\hline - Fatigue, mainly in the morning, with muscular \\
atrophia \\
\hline - Dyspepsia \\
\hline - Sexual disorders and dysfunction \\
\hline - Psychological asthenia \\
\hline - Memory loss \\
\hline
\end{tabular}

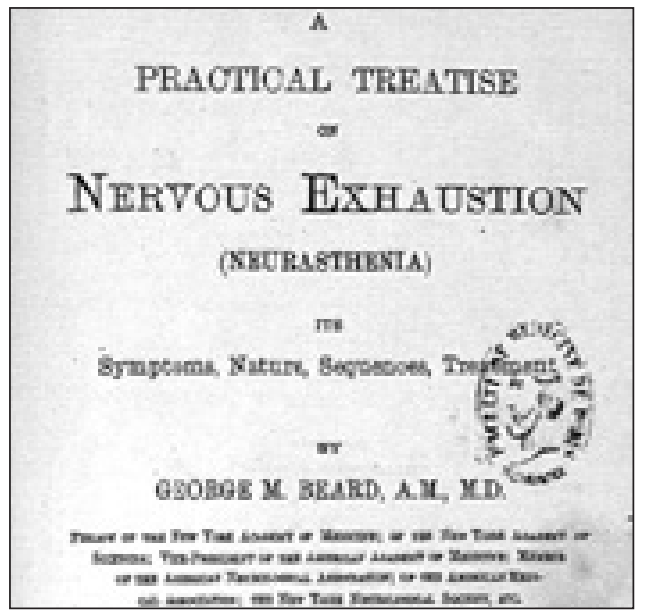

Figure 1 - Neurasthenia (Beard, 1869).

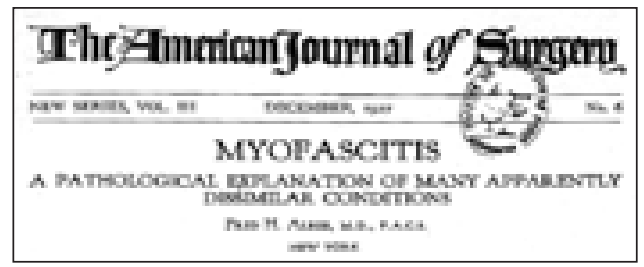

Figure 2 - Myofasciitis (Albee, 1927).

labels: myofibrositis mimicking other diseases (20), psychogenic rheumatism (21), and allergic myalgia (22) (Figure 2).

\section{Post-traumatic pain}

The Second World War was a period in which several descriptions were reported in male soldier patients. In 1942, Savage (23) demonstrated that in 2,727 visiting soldiers, 307 had rheumatic symptoms, and among them 52\% had fibrositis. In 1947: Boland (21) described "psychogenic rheumatism" in the army, with the description of this new clinical entity involving $24 \%$ of soldiers attending his hospital. There were biological and imaging abnormalities, and the clinical picture was considered linked to psychological stress. This is very close to another syndrome, described 50 years later, in 1991, the Gulf War syndrome (24). Finally, recent studies have not confirmed that fibromyalgia is a psychological disorder. Indeed, there are more anxiety and more depression in fibromyalgia, but also in all other chronic syndromes compared to healthy controls (25). Anxiety and depression increase when related to medical symptoms without identified pathology (26). There is no proven specific psychological feature or traits associated with fibromyalgia (27), whereas cognitive dysfunction and inefficient coping are severe (28).

From the 1950s, the stress theory: is fibromyalgia syndrome a stress-induced disorder with changes in the stress hormones? Many years after the theory of stress originated by the famous endocrinologist Hans Selye, in the 50s, there have been several studies on endocrine abnormalities of the hypothalamic-pituitary-adrenal (HPA) axis in fibromyalgia. These theories describe endocrine abnormalities of the hypothalamic- 
pituitary-adrenal (HPA) axis that result in a blunted adrenal cortisol response to ACTH with lowered 24-hour free cortisol levels in many patients with fibromyalgia (29). Other theories have looked at IGF1 and GH levels in fibromyalgia patients.

They have found low insulin-like growth factor (IGF1) in one-third of patients, resulting in decreased nocturnal growth hormone $(\mathrm{GH})$ secretion (30). In fact, hormonal dosages are not indicated for clinical use in patient care, but may have an impact on therapeutic approaches since several studies have demonstrated relevant effect of $\mathrm{GH}$ treatment in fibromyalgia (31).

The golden times: recognition of the disease, development of criteria, but still controversies

Between the 1970s and the 90s, recognition of the disease was an important step for patients but also for physicians: the disease received a name, diagnostic criteria, and assessment tools.

Naming the disease and official integration in the disease classification

In 1976, the Nobel Prize winner Hench described the term "fibromyalgia" as a nonarticular rheumatism. In 1990 the World Health Organization recognised fibromyalgia. Fibromyalgia was integrated into the International Classification of Diseases (ICD10) in the chapter on non-articular rheumatic diseases, with unknown aetiology, under the code M79-0. In 1987, the American Medical Association (AMA), recognized FMS as a true illness and a major cause of disability. In 1992, at the Second World Congress on Myofascial Pain and Fibromyalgia in Copenhagen, a consensus statement on fibromyalgia was agreed and published in The Lancet under the name "Copenhagen Declaration 1992" (32).

Concomitantly, several classification criteria have been proposed

In 1972, the first criteria to be proposed were published by Smythe (33). In the 1980 's, another researcher, Yunus, further clarified fibromyalgia by proposing the need for a unified classification system as well as the first diagnostic criteria. He was the first to popularize the word 'fibromyalgia' and in 1981 the Yunus criteria were released (34). Lastly, Wolfe et al. in 1990 published the most famous criteria under the name of ACR 1990 Classification Criteria (35).

\section{Several tools to assess fibromyalgia}

The first tool to assess fibromyalgia, the Fibromyalgia Impact Questionnaire (FIQ), was developed in the late 1980s by Burckhardt, Clark and Bennett at Oregon in Portland USA (36). Since that time FIQ has been extensively used as one of the main indexes of therapeutic efficacy in fibromyalgia. OMERACT, an independent organization primarily dedicated to rheumatoid arthritis developed its first workshop on fibromyalgia in 2004 (37) to define important and relevant research domains.

\section{Some controversies have emerged}

Immediately after 1990, when the American College of Rheumatology (ACR) classification criteria for fibromyalgia (35) were published, controversies emerged.

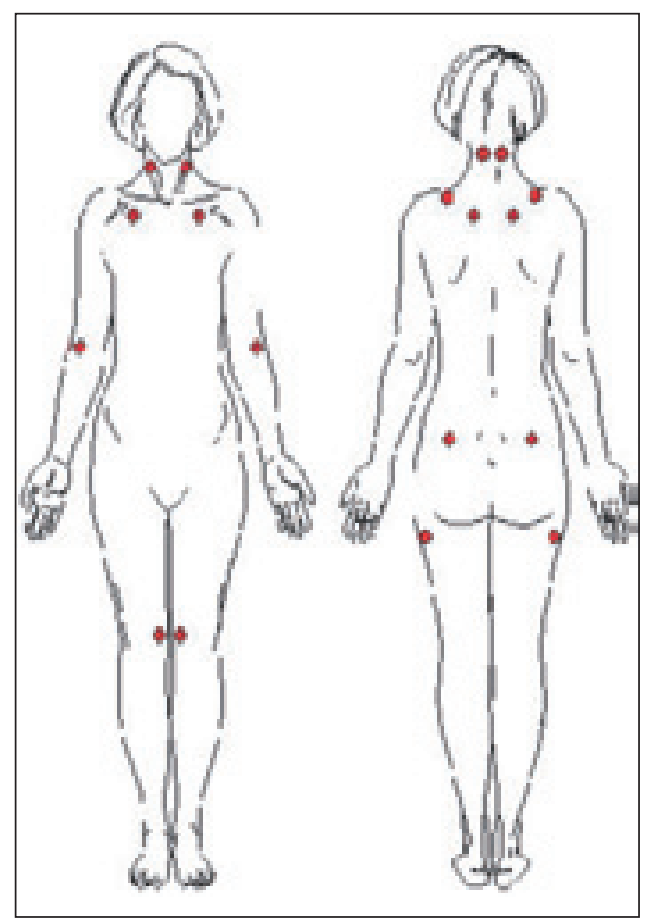

Figure 3 - Tender points. American College of Rheumatology (ACR), 1990. 


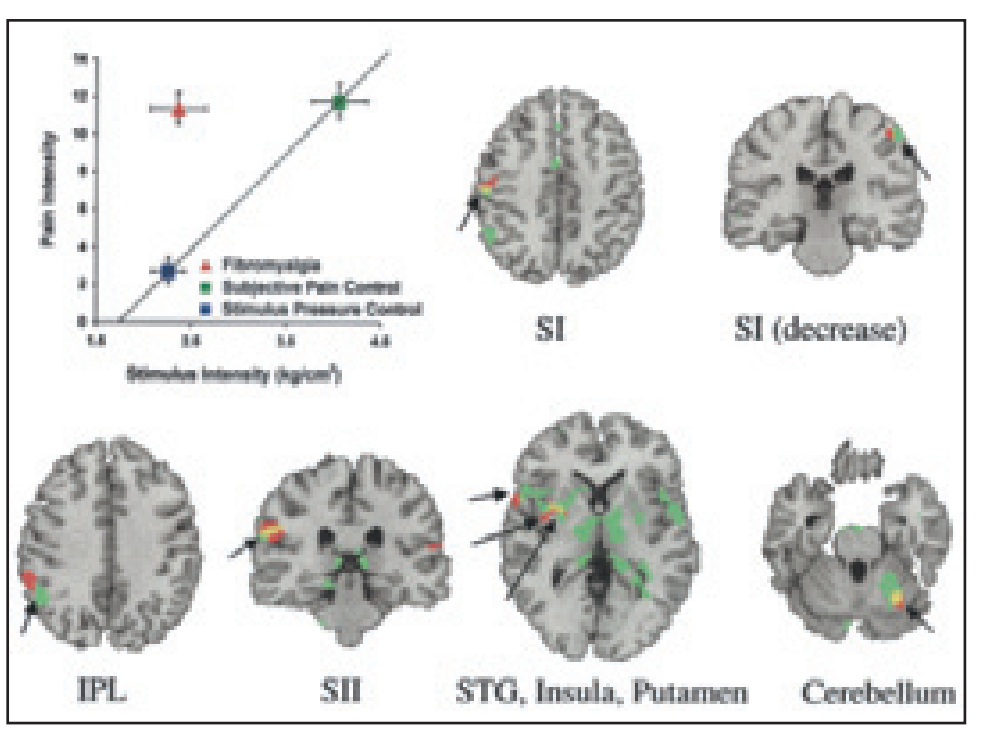

Figure 4 - Brain theory (Gracely, 2002).

ACR1990 criteria were primarily classification but not diagnostic criteria: the value of 11 tender points out of 18 was discussed, and important symptoms such as fatigue, sleep disturbances, and cognitive dysfunction are not included in the ACR criteria (38) (Figure 3).

\section{Sleep as a pathophysiological explanation}

Sleep disorders have been recently considered an important comorbid condition in fibromyalgia. In the 1970s, Moldofsky (39) performed the first scientific sleep studies in fibromyalgia and demonstrated the links between sleep disorders and fibromyalgia. The association between musculoskeletal symptoms and a non-REM or stage 4 sleep disturbance was demonstrated. Moldofsky proposed that fibrositis be considered a "nonrestorarive sleep syndrome." Although not specific to fibromyalgia, this irregular sleep pattern may be an important factor contributing to the severity of disease manifestations.

In the $21^{\text {st }}$ century, is everything genetically driven?

As in many diseases, a genetic predisposition has been evoked in fibromyalgia. An interesting study demonstrated familial aggregation in fibromyalgia (40). Much research, especially in Israel, has tried to identify genetic factors that may predispose to fibromyalgia (41). Most of the targets that have been studied are related to serotonin receptors and transporters, enzymes like COMT (42), and dopamine receptors.

The last chapter: the era of neurosciences: fibromyalgia is a dysfunctional disorder? A neuropathic pain?

The $21^{\text {st }}$ century can be considered the century of neurosciences, since there have been major findings in that scientific area.

\section{CNS imaging: fibromyalgia is real!}

CNS imaging has presented an important step for physicians in that it demonstrates that specific changes are observed in the patients' brain (43), suggesting to all physicians that finally fibromyalgia is real (Figure 4).

Is fibromyalgia a neurological condition? Concomitantly, other authors have suggested that fibromyalgia could be part of neuropathic disorders (44), and several works have investigated central nervous system changes in fibromyalgia (45). For example, there are modifications in the neuromediators, increased levels of substance $\mathrm{P}$ and nerve growth factor, and lowered levels of serotonin.

Is fibromyalgia a dysfunctional pain syndrome?

Not yet validated, but in discussion, the classification of pain disorders may incor-

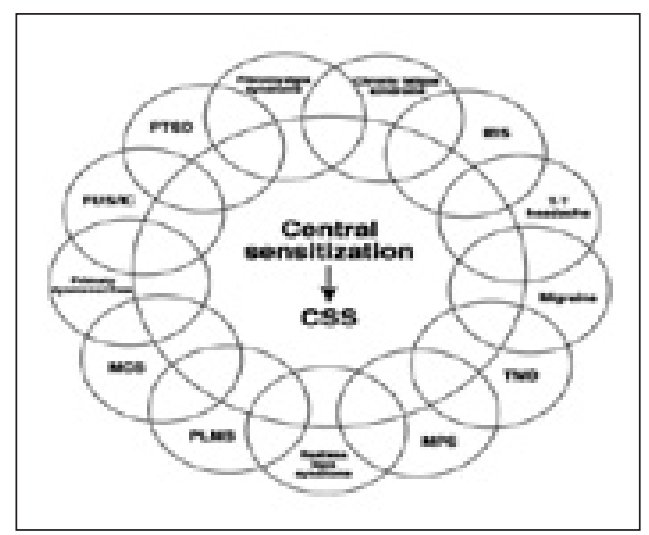

Figure 5 - Central sensitivity syndrome (Yunus, 2007). 
porate a new class of pain syndromes, the dysfunctional pain syndromes, including fibromyalgia, irritable bowel syndrome, restless leg syndrome, and cystalgia. Even if there are common mechanisms with neuropathic pain, this new class may definitely differentiate fibromyalgia from neuropathic pain syndromes, where a lesion of the neurological system is mandatory. This is close to another classification, proposed by Yunus (46), the concept of central sensitization syndromes (Figure 5). In fibromyalgia and dysfunctional pain syndromes, central pain sensitization (47) and lack of inhibitory endogenous pain controls (48) may explain the symptoms, and also the therapeutic issues.

\section{Fibromyalgia: a never ending story?}

The recent history of fibromyalgia is now very dynamic in several ways:

Diagnostic criteria. The new criteria, released by the ACR in 2010 (49) 20 years after the first classification criteria, tried to abandon tender point examination and establish diagnostic and severity criteria. To date, these criteria are not validated and still in discussion.

Therapeutic approaches. There is a growing discrepancy between Europe and North America in the availability of drugs for the treatment of fibromyalgia. The FDA (50) has approved 3 pharmacological treatments for pain in fibromyalgia: duloxetine, milnacipran and pregabalin, although EMA has rejected all the same dossiers, for different reasons, including the small number of European patients, weak efficacy (very small effect-sizes), and no evidence of a dose-effect relationship. These discrepancies also reflect the different social health systems.

Management recommendations. Although there is no drug licensed for fibromyalgia in Europe, several recommendations have been published: in 2006, EULAR developed recommendations (51), but other recommendations have been published in Germany and Spain.

Screening tools. Several screening tools have been developed to detect fibromyalgia more easily in clinical practice. A tool dedicated to screen fibromyalgia via phone calls has been proposed by Canadian authors: the LFESQ (52) as well as a simple tool to screen fibromyalgia in clinical practice, the FiRST (Fibromyalgia Rapid Screening Tool) (53).

Epidemiological data. Fibromyalgia epidemiological studies have represented an important step in demonstrating the prevalence of the disease. Most of these studies have led to similar data. In the US, fibromyalgia is estimated at around $3 \%$ of the adult population $(52,54)$. In Europe, the prevalence of fibromyalgia is also estimated between $1.6 \%$ in France (55) and 2.6\% in whole Europe (56).

\section{CONCLUSIONS}

In conclusion, the history of fibromyalgia is a story of controversies: the fight between subjectivity and cartesianism, and between old mind and body concepts. Fibromyalgia represents the emblematic condition of unexplained medical symptoms (57), far from well-defined diseases with objective biomarkers. It is the far end of medicine, sociology and psychology, addressing difficult questions to medical science. This exciting scientific history is not finished, but we do hope that this history will come to a time when patients will no longer be stigmatised. Even if no one denies that patients exist, there are still many "fibroskeptical" physicians and, as in the 1920 s, the question "is fibromyalgia real?" remains. It is time that medicine recognizes these patients and their condition, without any prejudice and with the best scientific evidence.

\section{REFERENCES}

1. Perrot S. Fibromyalgia syndrome: a relevant recent construction of an ancient condition? Curr Opin Support Palliat Care. 2008; 2: 122-7.

2. Hunter C. An address on fibrositis (myalgia, chronic muscular rheumatism). Can Med Assoc J. 1926; 16: 1319-24.

3. Hench PK. Nonarticular rheumatism. Arthritis Rheum. 1976; 19: 1088. 
4. Grossman BJ. Rheumatoid arthritis from prehistory to Hippocrates. Proc Inst Med Chic. 1966; 26: 114-5.

5. McIntyre N. Xavier Bichat (1771-1802). J Med Biogr. 2004; 12: 184.

6. Balfour W. Observations on the pathology and cure of rheumatism. Edinburgh Medical and Surgical Journal. 1815; 11: 168-87.

7. Valleix F-L-I. Traité des névralgies ou affections douloureuses des nerfs. Paris: J.-B. Baillière. 1841.

8. Inman T. Remarks on myalgia or muscular pain. Br Med J. 1858; 1: 407-8, 866-8.

9. Froriep R: Ein Beitrag zur Pathologie des Rheumatismus. Weimar, 1843.

10. Cornelius A. Narben und nerven. Deutsche militartzlische Zeitschrift. 1903; 32: 657-73.

11. Helleday U. Om mysitis chronica (rheumatica). Ett bidrag till dess diagnostik och behandling. Nord Med Arkiv. 1876; 8: 1-17.

12. Gowers W. A lecture on lumbago: Its lessons and analogues. Br Med J. 1904; 1: 117-21.

13. Stockman R. The causes, pathology and treatment of chronic rheumatism. Edinburgh Med. J 1904; 15: 107-16.

14. Bennett RM. Fibrositis: misnomer for a common rheumatic disorder. West J Med. 1981; 134: 405-13.

15. Telling W. Nodular Fibromyositis - an everiday affliction and its indentity with so-called muscular rheumatism. Lancet. 1911; 1: 154-8.

16. Cyriax J. Fibrositis. Br Med J. 1948; 2: 251-5.

17. Travell J, Rinzier $S$. The myofascial genesis of pain. Postgrad Med- 1952; 11: 425-34.

18. Bengtsson A. The muscle in fibromyalgia. Rheumatology (Oxford)- 2002; 41: 721-4.

19. Beard G. Neurosthenia or nervous exhaustion. Boston Med Surg J. 1869; 3: 217-20.

20. Murray G. Myofibrositis as simulator of other maladies. Lancet. 1929; 1: 113-6.

21. Boland EW. Psychogenic rheumatism: the musculoskeletal expression of psychoneurosis. Ann Rheum Dis- 1947; 6: 195-203.

22. Randolph TG. Allergic myalgia. J Mich State Med Soc. 1951; 50: 487-94.

23. Savage O. Rheumatic diseases in the forces. Br Med J. 1942; 2: 336-8.

24. Thomas HV, Stimpson NJ, Weightman A, et al. Pain in veterans of the Gulf War of 1991: a systematic review. BMC Musculoskelet Disord. 2006; 7: 74.

25. Henningsen P, Zimmermann T, Sattel H. Medically unexplained physical symptoms, anxiety, and depression: a meta-analytic review. J Psychosom Med. 2003; 65: 528-33.

26. Katon W, Sullivan M, Walker E. Medical symptoms without identified pathology: relationship to psychiatric disorders, childhood and adult trauma, and personality traits. Ann Intern Med. 2001; 134: 917-25.

27. Ekselius L, Bentsson A, von Knorring L. Personality traits as determined by means of the
Karolinska scales of personality in patients with fibromyalgia. J Musculoskel Pain 1998; 6: 35-49.

28. Glass JM. Review of cognitive dysfunction in fibromyalgia: a convergence on working memory and attentional control impairments. Rheum Dis Clin North Am. 2009; 35: 299-311.

29. Geenen R, Jacobs JW, Bijlsma JW. Evaluation and management of endocrine dysfunction in fibromyalgia. Rheum Dis Clin North Am. 2002; 28: 389-404.

30. Jones KD, Deodhar P, Lorentzen A, et al. Growth hormone perturbations in fibromyalgia: a review. Semin Arthritis Rheum. 2007; 36: 357-79.

31. Cuatrecasas G, Alegre C, Fernandez-Solà J, et al. Growth hormone treatment for sustained pain reduction and improvement in quality of life in severe fibromyalgia. Pain. 2012; 153: 1382-9.

32. Quintner J. Fibromyalgia: the Copenhagen declaration. Lancet. 1992; 340: 1103.

33. Smythe HA. Non-articular rheumatism and the fibrositis syndrome, Arthritis and Allied Conditions, 8th ed. Philadelphia, Lea and Febiger. 1972; 874-84.

34. Yunus M, Masi A, Calabro J, Miller K, Feigenbaum S. Primary fibromyalgia (fibrositis): clinical study of 50 patients with matechedcontrols. Seminars in Arthritis and Rheumatism. 1981; 11: 151-71.

35. Wolfe F, Smythe HA, Yunus MB, et al. The American College of Rheumatology 1990 Criteria for the Classification of Fibromyalgia. Report of the Multicenter Criteria Committee. Arthritis Rheum. 1990; 33: 160-72.

36. Burckhardt CS, Clark SR, Bennett RM. The fibromyalgia impact questionnaire: development and validation. J Rheumatol. 1991; 18 : 728-33.

37. Mease PJ, Clauw DJ, Arnold LM, et al. Fibromyalgia syndrome. J Rheumatol. 2005; 32: 2270-7.

38. Aaron LA, Buchwald D. Chronic diffuse musculoskeletal pain, fibromyalgia and co-morbid unexplained clinical conditions. Best Pract Res Clin Rheumatol. 2003; 17: 563-74.

39. Moldofsky H, Scarisbrick P, England R, Smythe H. Musculoskeletal symptoms and non-REM sleep disturbance in patients with «fibrositis syndrome» and healthy subjects. Psychosom Med. 1975; 37: 341-51.

40. Arnold LM, Hudson JI, Hess EV, et al. Family study of fibromyalgia. Arthritis Rheum. 2004; 50: 944-52.

41. Buskila D, Sarzi-Puttini P. Biology and therapy of fibromyalgia. Genetic aspects of fibromyalgia syndrome. Arthritis Res Ther. 2006; 8:.218.

42. Gursoy S, Erdal E, Herken H, et al. Significance of catechol-O-methyltransferase gene polymorphism in fibromyalgia syndrome. Rheumatol Int. 2003; 23: 104-7. 
43. Gracely RH, Petzke F, Wolf JM, Clauw DJ. Functional magnetic resonance imaging evidence of augmented pain processing in fibromyalgia. Arthritis Rheum. 2002; 46: 1333-43.

44. Dworkin RH, Fields HL. Fibromyalgia from the perspective of neuropathic pain. J Rheumatol. (Suppl.) 2005; 75: 1-5.

45. Russell IJ, Orr MD, Littman B, et al. Elevated cerebrospinal fluid levels of substance $\mathrm{P}$ in patients with the fibromyalgia syndrome. Arthritis Rheum. 1994; 37: 1593-601.

46. Yunus MB. Fibromyalgia and overlapping disorders: the unifying concept of central sensitivity syndromes. Semin Arthritis Rheum. 2007; 36: 339-56.

47. Desmeules JA, Cedraschi C, Rapiti E, et al. Neurophysiologic evidence for a central sensitization in patients with fibromyalgia. Arthritis Rheum. 2003; 48: 1420-9.

48. Kosek E, Hansson P. Modulatory influence on somatosensory perception from vibration and heterotopic noxious conditioning stimulation (HNCS) in fibromyalgia patients and healthy subjects. Pain. 1997; 70: 41-51.

49. Wolfe F, Clauw DJ, Fitzcharles MA, et al. The American College of Rheumatology preliminary diagnostic criteria for fibromyalgia and measurement of symptom severity. Arthritis Care Res (Hoboken). 2010; 62: 600-10.

50. Peck P. Pregabalin (lyrica) is first drug approved for fibromyalgia. MedPage Today: News Brief. Accessed September 24, 2007. Available from: http://www.medpagetoday.com/Rheumatol-
ogy/GeneralRheumatology/tb/5992.

51. Carville SF, Arendt-Nielsen S, Bliddal H, et al. EULAR evidence-based recommendations for the management of fibromyalgia syndrome. Ann Rheum Dis. 2008; 67: 536-41.

52. White KP, Harth M, Speechley M, Ostbye T. Testing an instrument to screen for fibromyalgia syndrome in general population studies: the London Fibromyalgia Epidemiology Study Screening Questionnaire. J Rheumatol. 1999; 26: 880-4.

53. Perrot S, Bouhassira D, Fermanian J. Cercle d'Etude de la Douleur en Rhumatologie. Development and validation of the Fibromyalgia Rapid Screening Tool (FiRST). Pain. 2010; 150: 250-6.

54. Neumann L, Buskila D. Epidemiology of fibromyalgia. Curr Pain Headache Rep. 2003; 7: 362-8.

55. Perrot S, Vicaut E, Servant D, Ravaud P. Prevalence of fibromyalgia in France: a multi-step study research combining national screening and clinical confirmation: The DEFI study (Determination of Epidemiology of FIbromyalgia). BMC Musculoskelet Disord. 2011; 12: 224.

56. Branco JC, Bannwarth B, Failde I, et al. Prevalence of fibromyalgia: a survey in five European countries. Semin Arthritis Rheum. 2010; 39: 448-53.

57. Kroenke K, Rosmalen JG. Symptoms, syndromes, and the value of psychiatric diagnostics in patients who have functional somatic disorders. Med Clin North Am. 2006; 90: 603-26. 